\title{
MAPEAMENTO \\ DOS ESTUDOS \\ SOBRE POLÍTICAS \\ LINGUÍSTICAS E \\ INTERNACIONALIZAÇÃO \\ NO BRASIL: \\ UMA SELFIE
}

\author{
MAPEO DE LOS ESTUDIOS SOBRE POLÍTICAS LINGÜÍSTICAS E \\ INTERNACIONALIZACIÓN EN BRASIL: UN SELFIE
}

MAPPING STUDIES ON LANGUAGE POLICIES AND INTERNATIONALIZATION IN BRAZIL: A SELFIE

Renata Mourão Guimarães*

Instituto Federal de Brasília

Lauro Sérgio Machado Pereira**

Instituto Federal do Norte de Minas Gerais

RESUMO: Este estudo mapeou e discutiu trabalhos que tratam da internacionalização da educação na sua interface com políticas linguísticas, de Programas de Pós-Graduação em Letras e Linguística no Brasil, entre 2009 a 2019. Trata-se de pesquisa bibliográfica, no Catálogo de Teses e Dissertações da Capes (BTD) e na Biblioteca Digital Brasileira de Teses e Dissertações (BDTD). A partir das teses e dissertações investigadas, é possível perceber: a) interesse crescente da área por essas temáticas, afirmando o caráter inter/transdisciplinar dos estudos de linguagem e a relevância das línguas na internacionalização; b) predomínio de pesquisas no eixo Sul-Sudeste; c) foco em programas de governo; d) estudos em contexto de ensino de inglês e francês. Assim, apontamos necessidade de estudos em contexto de outras línguas e enfoques, e de pesquisas que discutam alternativas para estratégias tradicionais de internacionalização e para o rompimento de práticas hegemônicas e excludentes de linguagem.

PALAVRAS-CHAVE: Políticas Linguísticas. Internacionalização. Educação

\footnotetext{
* Professora de Língua Espanhola do Instituto Federal de Brasília (IfB). Mestre em Linguística Aplicada pela Universidade de Brasília (UnB) e doutoranda em Linguística pela mesma universidade. E-mail: renataguimaraes.rmg@gmail.com.

** Professor de Língua Inglesa do Instituto Federal do Norte de Minas Gerais (IFNMG). Mestre em Linguística Aplicada pela Universidade de Brasília (UnB) e doutorando em Linguística pela mesma universidade. E-mail: lauro.pereira@ifnmg.edu.br.
} 
RESUMEN: Este estudio mapeó y discutió trabajos que abordan la internacionalización de la educación en su interfaz con políticas lingüísticas, de Programas de Posgrado en Letras y Lingüística en Brasil, entre 2009 y 2019. Se trata de una investigación bibliográfica, en el Catálogo de Tesis y Disertaciones de la Capes (BTD) y en la Biblioteca Digital Brasileña de Tesis y Disertaciones (BDTD). A partir de los trabajos investigados, se percibe: a) un creciente interés del área por estos temas, afirmando el carácter inter/transdisciplinar de los estudios del lenguaje y la relevancia de las lenguas en la internacionalización; b) un predominio de investigación en el eje Sur-Sureste; c) la centralidad en programas gubernamentales; d) estudios en contexto de enseñanza de inglés y francés. Así, señalamos la necesidad de estudios en el contexto de otras lenguas y enfoques, y de investigaciones que discutan alternativas para estrategias tradicionales de internacionalización y para la ruptura de prácticas lingüísticas hegemónicas y excluyentes.

PALABRAS CLAVE: Políticas lingüísticas. Internacionalización. Educación.

ABSTRACT: This study mapped and discussed works that deal with the internationalization of education in its interface with language policies, from Postgraduate Programs in Letters and Linguistics in Brazil, between 2009 and 2019. It is a state-of-the-art bibliographic research, in the Catalog Capes Theses and Dissertations (BTD) and in the Brazilian Digital Library of Theses and Dissertations (BDTD). From the investigated theses and dissertations, it is possible to notice: a) the area's growing interest in these themes, affirming the inter/transdisciplinary character of language studies and the relevance of languages in internationalization; $b$ ) predominance of research in the South-Southeast axis; c) focus on government programs; d) studies in the context of English and French teaching. Thus, we point out the need for studies in the context of other languages and approaches, and for researches that discuss alternatives to traditional internationalization strategies and to break with hegemonic and excluding language practices. KEYWORDS: Language Policies. Internationalization. Education.

\section{INTRODUÇÃO}

A internacionalização da educação tem se destacado nas últimas duas décadas, na agenda das instituições de nível superior, contudo, sua prática é antiga. Se considerarmos o contexto mundial, a internacionalização da educação data da Idade Média, desde a criação das universitas, comunidades universais formadas por mestres e alunos de toda parte do mundo associados por interesses comuns de conhecimento (VEIGA, 2007; STALLIVIERI, 2017). E, se levarmos em conta o contexto brasileiro, pode-se notar que, entre as décadas de 1930 e 1950, já existiam algumas iniciativas, por meio de programas de cooperação com ênfase nas missões que traziam professores visitantes às universidades brasileiras (LIMA; CONTEL, 2011).

Por um prisma mais amplo, atribui-se o atual fenômeno da internacionalização à globalização. O discurso da globalização para justificar as mudanças ocorridas, especialmente, a partir da década de 1990, desde os sistemas produtivos à revolução das Tecnologias de Informação e Comunicação (TIC), tem sido utilizado em diferentes campos das ciências, embora com diferentes perspectivas e acepções (SANTOS, 2011; TEODORO, 2003). Tais mudanças sentidas em âmbito social, cultural, econômico e político incidem nos sentidos e parâmetros educacionais, na medida em que se buscam preparar pessoas para lidarem com aspectos desse sistema global. Em face dessa nova conjuntura, a internacionalização vai ocupando lugar nos discursos e nas políticas educativas em todo o mundo.

A internacionalização da educação é vista, nesse sentido, como reagente ou agente da globalização. Como reagente da globalização é influenciada pelos organismos multilaterais, como Banco Mundial, Organização Mundial do Comércio (OMC), Organização para a Cooperação e o Desenvolvimento Econômico (OCDE), Organização das Nações Unidas para a Educação, a Ciência e a Cultura (Unesco); pelas regiões e países ricos, tornando-se refém da falta de subsídio público e dos padrões de competitividade, da ampliação de mercado e de serviços (LIMA; CONTEL, 2011). Como agente, a internacionalização serve-se da globalização, potencialmente em prol da educação crítica, da troca de conhecimentos, da pesquisa e do ensino com base no desenvolvimento humano, remetendo-nos a uma visão mais solidária, acadêmica e ética do processo (DE WIT, 2013).

A internacionalização da educação é transversal a todas as funções da universidade: ensino, pesquisa e extensão. Trata-se de um fenômeno heterogêneo, multifacetado, não neutral com diferentes significados, razões, motivações, perspectivas e agentes (OREGIONI, 2015, 2017; PERROTTA, 2016; MOROSINI, 2019).

Guimarães \& Pereira | Mapeamento dos estudos sobrepolíticas linguísticas e internacionalização no Brasil... 
O conceito de internacionalização não será problematizado no decorrer deste trabalho, no entanto, em termos gerais e para efeito de introdução, podemos dizer que a internacionalização da educação é a relação de cooperação, troca, compartilhamento epistêmico, científico e tecnológico entre países, comunidades, culturas, instituições e pessoas, construída na interação. Embora essa relação não seja, habitualmente, simétrica, recíproca e solidária, podemos dizer que a internacionalização da educação tem sido fundamental para a produção de conhecimento e para a geração de respostas a desafios comuns.

Muitos pesquisadores têm adotado o discurso da inevitabilidade da internacionalização educacional, assinalando que internacionalizar não é mais uma opção, mas sim uma forma de sobrevivência, um imperativo institucional e não apenas uma possibilidade desejável (STALLIVIERI, 2017; HUDZIK, 2011). Nessa lógica, a internacionalização vai se constituindo "em uma ameaça simbólica, uma espada sobre a cabeça dos gestores e de muitos que estão imbricados com o assunto" (MOROSINI, 2019, p.11). Consideramos, assim, que para além da imperatividade e obrigatoriedade, a internacionalização possa ser vista como intencionalidade e democratização do acesso ao conhecimento, cultura, ciência e tecnologia.

Segundo Morosini (2019), o tema internacionalização da educação superior está em acelerada expansão. Até 2013, a produção brasileira em teses e dissertações era pequena e não ultrapassava o quantitativo de 23 estudos. Atualmente, podemos dizer que esse número aumentou consideravelmente. A partir de um levantamento de teses e dissertações de Programas de Pós-Graduação brasileiros, foram encontradas 114 dissertações e sessenta teses que versam sobre internacionalização da educação, totalizando 174 estudos até o ano de 2019. Observamos que a temática internacionalização da educação tem sido alvo de interesse, principalmente, da área de Ciências Sociais Aplicadas, mais especificamente da Administração e da Economia, e de Ciências Humanas, em estudos da Sociologia, Ciência Política e Educação. Tais estudos têm contemplado a descrição, análise e/ou avaliação de programas de governo ou de estratégias institucionais isoladas, em sua maioria estudos de caso.

Morosini (2019) observa que, na América Latina e no Brasil, autores e centros consolidados que discutem internacionalização são poucos, se comparados com a América do Norte, Canadá, Estados Unidos e União Europeia. Ao comparar a produção dos países do Norte Global com os do Sul Global ${ }^{1}$, a autora salienta que no Norte predomina a pesquisa de como fazer a internacionalização, já no Sul são discutidas questões críticas sobre o tema, conceitos e suas relações com os organismos multilaterais. Consideramos tais perspectivas de estudos do Sul Global relevantes, no sentido de problematizar a lógica embutida nas relações de cooperação, de deslocar o pensamento para outras possibilidades de internacionalização da educação pública brasileira, idealizando alternativas e perspectivas desvinculadas da perspectiva hegemônica e passiva pautada por uma orientação mercadológica de educação.

Apesar de ser tema comumente explorado em Ciências Sociais Aplicadas e em Ciências Humanas, a área de Letras e Linguística ${ }^{2}$ tem se debruçado também sobre a internacionalização da educação, no tocante à sua dimensão linguística. No cerne da internacionalização, as línguas estrangeiras/adicionais (LE/A $)^{3}$ assumem papel fundamental, o que tem impulsionado reflexões em torno da relação entre internacionalização e políticas linguísticas (PLs) (GUIMARÃES; FINARDI; CASOTTI, 2019).

As PLs tomam a língua em seu caráter inerentemente político e podem ser consideradas como um conjunto de atividades referentes "[...] à política, ao planejamento, à planificação, à proteção, à manutenção, ao cultivo e [...] ao ensino da(s) língua(s) [...] de um povo" (RAJAGOPALAN, 2014, p. 73). Constitui-se em um mecanismo de política que impacta a estrutura, a função, o uso ou a

\footnotetext{
${ }^{1}$ Divisões epistemológicas que se sobrepõem à geografia da linha do Equador. O Sul Global é constituído por países e regiões submetidos ao colonialismo europeu e que não atingiram o desenvolvimento socioeconômico semelhante ao do Norte Global, responsável pela produção de ideologias. "Sul Global" e "Norte Global" são termos usados em estudos decoloniais para expressar uma relação desigual de saber-poder que suprimiu muitas formas de conhecimento próprias dos povos e/ou nações colonizados (SANTOS; MENESES, 2010). ${ }^{2}$ A área de Letras e Linguística compreende estudos linguísticos, literários, de tradução, culturais, aplicados etc., cujo enfoque crítico, teórico, descritivo e analítico
tem como objeto a língua e a literatura em seus mais variados escopos e perspectivas (BRASIL, 2019b).

${ }^{3} \mathrm{Na}$ área de linguagens, tem-se utilizado diferentes termos para denominar as línguas acrescidas/aprendidas/adquiridas pelos alunos, tais como Língua Estrangeira (LE), Língua Adicional (LA), Segunda Língua (L2). Apesar de entendermos que a terminologia "Língua Adicional" se constitui uma denominação mais neutra, não faremos distinção entre LE e LA no decorrer do texto, uma vez que os trabalhos referenciados utilizam um ou outro.
} 
aquisição/aprendizagem de uma língua, incluindo as regulações oficiais, as práticas não oficiais, os processos de criação, interpretação e apropriação pelos agentes, os textos e os discursos de política, bem com as camadas da atividade política influenciadas por ideologias (JOHNSON, 2013).

Nessa lógica, as políticas linguísticas passam a ser uma estratégia do processo de internacionalização materializadas por meio de programas na esfera nacional e internacional, como o Idiomas sem Fronteiras (IsF), exames de proficiência internacionais ${ }^{4}$ e de ações locais, por meio de cursos de línguas, testes de nivelamento, eventos científicos e culturais, webinários, palestras e workshops, grupos de estudos, aulas em LE/A nas metodologias CBI, EMI, CLIL ${ }^{5}$ e suas derivações, pela inclusão no currículo de temas interculturais e globais, bibliografia em LE/A, produção/comunicação científica e acadêmica, portal institucional plurilíngue, acolhimento e integração de alunos estrangeiros, uso das TIC nas interações com parceiros no exterior etc.

Levando em consideração a temática emergente, bem como o interesse por parte da área de linguagem pela internacionalização da educação, mapeamos e discutimos as produções acadêmicas nacionais de pós-graduação (teses e dissertações) acerca da internacionalização de diferentes níveis educacionais na sua interface com as políticas linguísticas, no período compreendido entre 2009 a 2019 (uma década), a fim de identificar o estado da arte desse campo, para a área de Letras e Linguística.

Segundo Ferreira (2002, p. 257),

[...] as pesquisas denominadas "Estado da Arte" têm caráter bibliográfico, e elas parecem trazer em comum o desafio de mapear e de discutir certa produção acadêmica em diferentes campos do conhecimento, tentando responder que aspectos e dimensões vêm sendo destacados e privilegiados em diferentes épocas e lugares, de que formas e em que condições têm sido produzidas certas dissertações de mestrado, teses de doutorado, publicações em periódicos e comunicações em anais de congressos e de seminários.

Trata-se, portanto, de uma pesquisa bibliográfica de estado da arte em que mapeamos e discutimos produções acadêmicas na pósgraduação de Letras e Linguística, na tentativa de apontar tendências, identificar lacunas e contribuir com o avanço da ciência nesta área do conhecimento.

\section{RETRATO DAS PESQUISAS SOBRE POLÍTICAS LINGUÍSTICAS PARA INTERNACIONALIZAÇÃO EM CONTEXTO DE PÓS-GRADUAÇÃO BRASILEIRA: FOCO, ENQUADRAMENTO E REVELAÇÃO PELAS LENTES DE LETRAS E LINGUÍSTICA}

Os trabalhos foram levantados no Banco de Teses e Dissertações da Comissão de Aperfeiçoamento de Pessoal do Nível Superior (Capes) (BTC) e na Biblioteca Digital Brasileira de Teses e Dissertações (BDTD), vinculada ao Instituto Brasileiro de Informação em Ciência e Tecnologia (IBICT). A busca foi realizada pela palavra-chave 'internacionalização' conjugada com a opção para área 'Letras e Linguística', com filtro para ano de publicação '2009 a 2019' e ordenação por data 'descendente'. Foram encontrados 67 trabalhos, sendo 39 dissertações e 28 teses, na BTC. Na BDTD foram encontrados 963 trabalhos, uma vez que o filtro para a área do conhecimento não estava disponível.

\footnotetext{
${ }^{4}$ Os principais exames de proficiência oficiais são: Inglês: TOEFL (Test of English as a Foreign Language), IELTS (International English Language Testing System) e Cambridge Test (FCE - First Certificate in English; CAE - Certificate of Advanced English; CPE - Proficiency); Espanhol: DELE (Diploma de Espanhol como Língua Estrangeira) e SIELE (Serviço Internacional de Avaliação da Língua Espanhola); Francês: DELF (Diplôme d'Etudes en Langue Française), DALF (Diplôme Approfondi de Langue Française), TCF (Test de Connaissance du Français), TEF (Test d'Evaluation de Français); Alemão: Goethe-Zertifikat, TestDaF (Deutsch als Fremdsprache); Chinês/Mandarim: HSK (Hanyu Shuiping Kaoshi), YCT (Youth Chinese Test) e BTC (Business Chinese Test); Português (Brasil): Celpe-Bras (Certificado de Proficiência em Língua Portuguesa para Estrangeiros).
}

${ }^{5}$ Content-based instruction (CBI); English as a Medium of Instruction (EMI) e Content and Language Integrated Learning (CLIL).

Guimarães \& Pereira Mapeamento dos estudos sobre políticas linguísticas e internacionalização no Brasil.. 
Entretanto, após a consulta minuciosa aos trabalhos, com verificação da área, leitura dos resumos e comparação entre as duas bases de dados, esse número foi reduzido para 33, pois apenas esses atendiam efetivamente às características do objeto do estudo: políticas linguísticas e internacionalização, fazendo referência no título, resumo e/ou palavras-chave.

As teses e dissertações foram sistematizadas e organizadas em um banco de dados de documento formatável, constituído por uma tabela com dois descritores: informações gerais/institucionais (ano, natureza da pesquisa, programa de pós-graduação, instituição de ensino e região) e informações sobre o estudo (título, autor, objeto/assunto/temática).

\subsection{FOTO PANORÂMICA COM DATA E LOCAL}

Foram analisadas dezoito dissertações e quinze teses, totalizando 33 trabalhos (Gráfico 1), disponíveis em programas de área de Letras e Linguística, com variações de nomenclatura dos programas, dos quais: Letras, Linguística, Linguística Aplicada, Estudos da Linguagem, Estudos Linguísticos, Língua e Cultura.

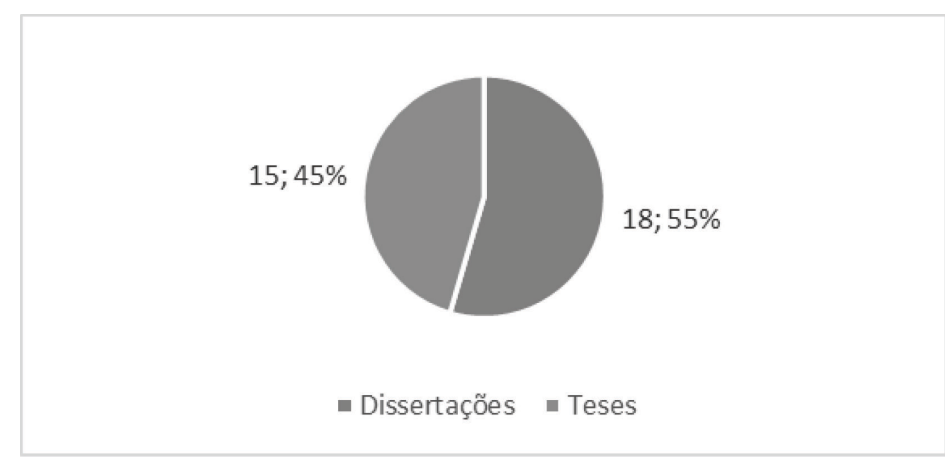

Gráfico 1: Quantitativo de estudos analisados

Fonte: Elaborado pelos autores

A partir do Gráfico 2, é possível perceber um aumento de pesquisas em nível de mestrado e doutorado, que versam sobre políticas linguísticas e internacionalização, na área de Letras e Linguística, nos últimos cinco anos. Podemos observar que o ano de 2017 concentra a maior parte dos trabalhos produzidos sobre o tema, e o ano de 2018 confirma o interesse por parte da área.

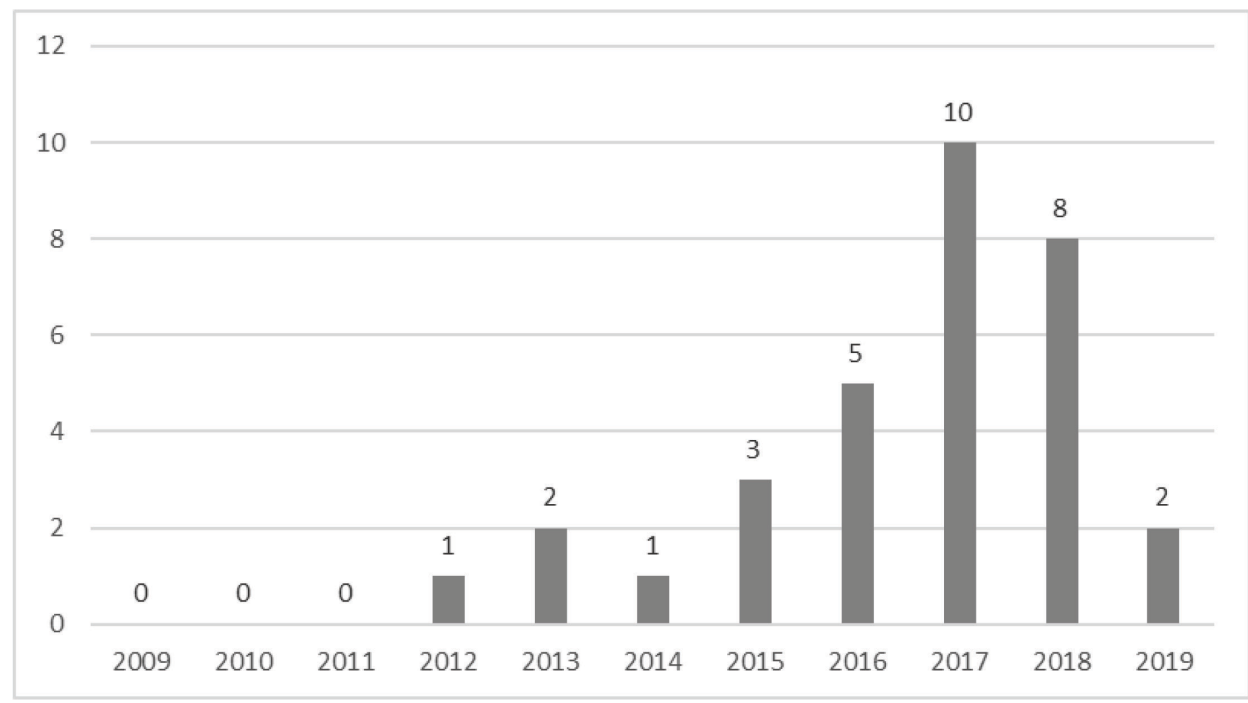

Gráfico 2: Produções de Pós-Graduação na área de Letras e Linguística no Brasil sobre PL e internacionalização, entre 2009 a 2019.

Fonte: Elaborado pelos autores 
O aumento de pesquisas pode ser justificado pela maior evidência de programas e convênios internacionais firmados nos últimos anos, entre eles o Ciência sem Fronteiras (2011), o Inglês sem Fronteiras (2012) e o Idiomas sem Fronteiras (2014), e o espaço de tempo para avaliação dos seus impactos.

Considerando as cinco regiões brasileiras (Norte, Nordeste, Sul, Sudeste e Centro-Oeste), somente a região Norte não possui estudos dessa natureza, e a região Sudeste é a que apresenta o maior número de produções, seguida da região Sul. Logo, há predominância de pesquisas no eixo Sul-Sudeste, representando 85\% das produções científicas. Das 27 unidades federativas brasileiras (26 estados e o Distrito Federal), nove contam com pesquisas, com predominância no estado de São Paulo, com onze estudos, e em seguida Paraná e Rio Grande do Sul, com cinco trabalhos respectivamente, conforme ilustrado nos gráficos a seguir (Gráficos 3 e 4).

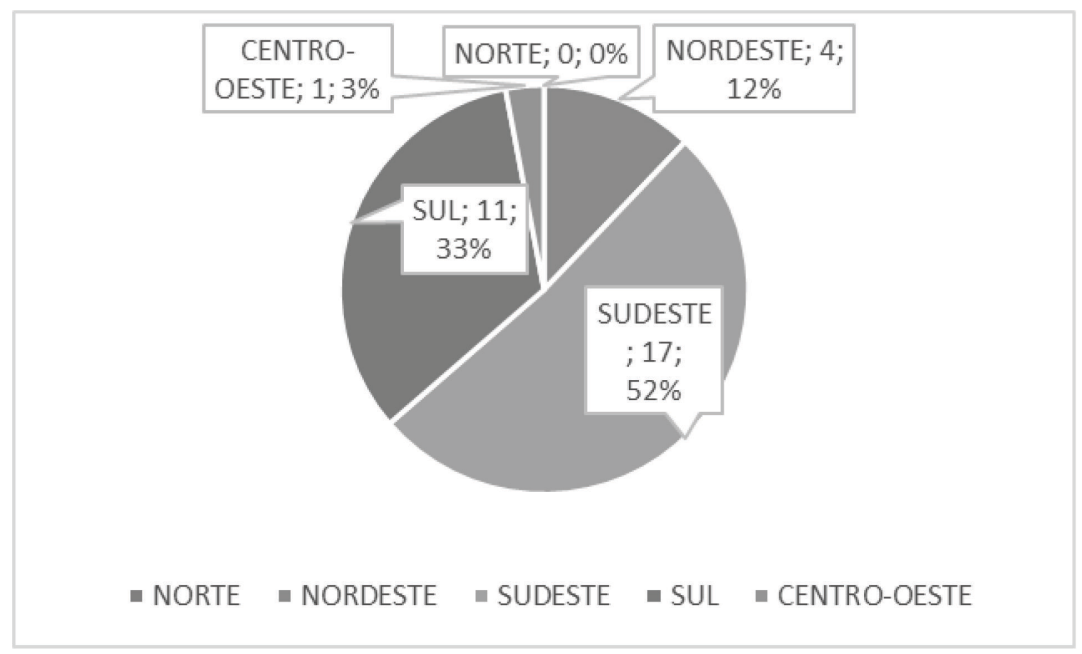

Gráfico 3: Regiões brasileiras com estudos sobre PL e internacionalização, entre 2009 a 2019.

Fonte: Elaborado pelos autores

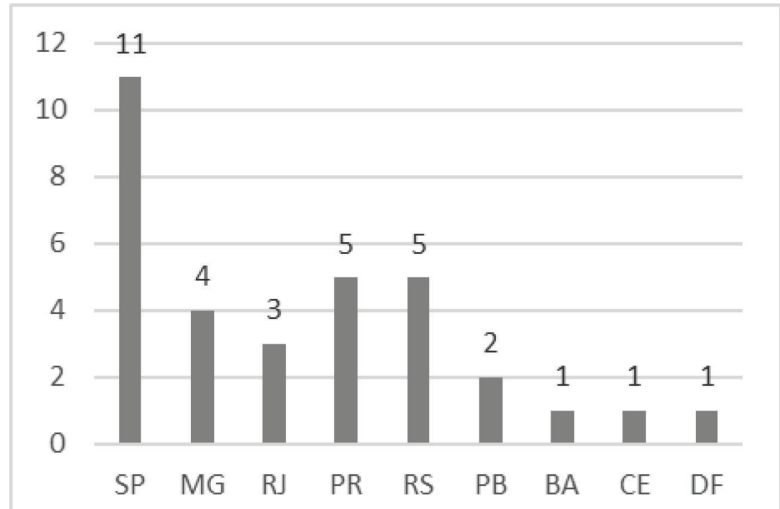

Gráfico 4: Unidades federativas com estudos sobre PL e internacionalização, entre 2009 a 2019.

Fonte: Elaborado pelos autores

No quadro a seguir (Quadro 1), é possível verificar que entre as universidades, as do estado de São Paulo apresentam maior representatividade, com um total de onze trabalhos, sendo sete produzidos na Universidade de São Paulo (USP) e quatro na Universidade Estadual de Campinas (Unicamp). 


\begin{tabular}{|c|c|c|}
\hline Universidade & Estado & Total \\
\hline 1. Universidade de São Paulo & SP & 7 \\
\hline 2. Universidade Estadual de Campinas & SP & 4 \\
\hline 3. Universidade Federal de Minas Gerais & MG & 3 \\
\hline 4. Universidade Federal Fluminense & RJ & 2 \\
\hline 5. Universidade Federal da Paraíba & $\mathrm{PB}$ & 2 \\
\hline 6. Universidade Estadual de Londrina & $\mathrm{PR}$ & 2 \\
\hline 7. Universidade Federal do Paraná & $\mathrm{PR}$ & 2 \\
\hline 8. Universidade Federal do Rio Grande Do Sul & RS & 2 \\
\hline 9. Pontifícia Universidade Católica do Rio de Janeiro & RJ & 1 \\
\hline 10. Universidade Federal do Ceará & $\mathrm{CE}$ & 1 \\
\hline 11. Universidade Federal de São João Del-Rei & MG & 1 \\
\hline 12. Universidade Federal da Bahia & $\mathrm{BA}$ & 1 \\
\hline 13. Universidade Federal de Viçosa & $\mathrm{MG}$ & 1 \\
\hline 14. Universidade Estadual de Maringá & $\mathrm{PR}$ & 1 \\
\hline 15. Universidade de Brasília & $\mathrm{DF}$ & 1 \\
\hline 16. Universidade do Vale do Rio Dos Sinos & RS & 1 \\
\hline 17. Universidade de Caxias Do Sul & RS & 1 \\
\hline 18. Universidade Federal de Pelotas & RS & 1 \\
\hline
\end{tabular}

Quadro 1: Universidades Federais e Estaduais que apresentam trabalhos sobre PL e internacionalização (2009-19)

Fonte: Elaborado pelos autores

A educação linguística, em sua abordagem geopolítica (RAJAGOPALAN, 2005), considera o uso de LE/A por uma série de motivações econômicas e culturais. Nesse caso, entendemos que no eixo Sul-Sudeste, e especialmente no Sudeste, a maior região geoeconômica do país, existe interesse na implementação das práticas de LE/A, por um motivo ou outro, geopolítico. Depreendemos, também, que a instituição, ao abrir espaço para essas discussões, implementa e promove uma força que movimenta tanto a internacionalização da própria universidade, como discussões no tocante a ela, em programas de pós-graduação e grupos de pesquisa, contribuindo para a teoria e para a prática de ações educativas contemporâneas. 


\subsection{FOTO SEM FILTRO: O CENÁRIO E OS ATORES}

A partir da leitura do título e da análise dos resumos, identificamos o objeto ou a temática do estudo. O conjunto total de referências selecionadas foram classificadas em torno de 5 temas: programas de governo; estratégias/programas locais; mobilidade; sentidos/processo de internacionalização; práticas de linguagem.

Apesar de alguns trabalhos ressaltarem mais de uma das temáticas elencadas, consideramos como objeto a exposta nos objetivos e nos resultados dos estudos. Após a exploração dos 33 registros, os descritores foram distribuídos, conforme o gráfico a seguir (Gráfico 5).

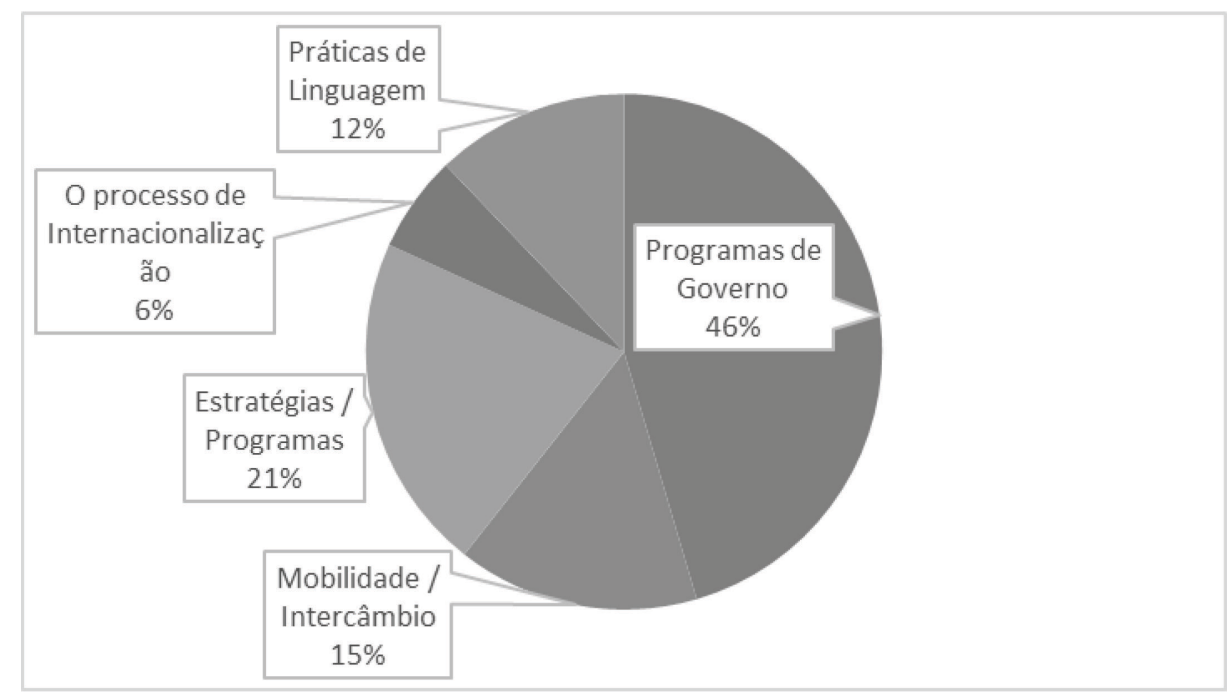

Gráfico 5: Descritores do objeto ou temática do estudo

Fonte: Elaborado pelos autores

O principal tema de estudo identificado, com 46\% de frequência, foi o de programas de governo, isto é, programas em nível nacional. Este tema de estudo refere-se, principalmente, aos programas: Ciências sem Fronteiras (CsF), Inglês (Idiomas) sem Fronteiras (IsF), Programa de Estudantes Convênio de Graduação (PEC-G), Certificado de Proficiência em Língua Portuguesa para Estrangeiros (Celpe-Bras) e Programa Leitorado.

Com frequência de $21 \%$, o segundo tema de estudo mais assíduo foi sobre diferentes estratégias/programas institucionais, com foco em ações locais no currículo, diplomação, curso de línguas etc.

Com $15 \%$, estudos sobre mobilidade acadêmica ou intercâmbio, que contam com questões relacionadas aos desafios culturais e linguísticos do aluno intercambista, e formação linguística para essa prática. Apesar de considerarmos que a mobilidade seja uma estratégia de internacionalização, optamos por separá-la do grupo anterior, por ela ter sido a mais representativa nos estudos.

Com $12 \%$, encontram-se estudos que tratam de práticas de linguagem, os quais caracterizam trabalhos que discutem letramentos acadêmicos, que, dentre outras características, voltam-se para os estudos sobre a escrita acadêmica e divulgação científica. Com 6\% de ocorrência, foi identificado o tema sentidos/processo de internacionalização, com foco na problematização desse construto e de sua construção localmente.

Ressaltamos, ainda, que os agentes dos estudos foram alunos brasileiros e/ou estrangeiros, docentes de línguas atuantes e em formação, e gestores. O contexto das pesquisas variou entre a educação superior, educação profissional, licenciatura em Letras, escola bilíngue e cursos (centros) de línguas. 
Entre os programas de governo de internacionalização, ativos e citados na página do Ministério da Educação (MEC) ${ }^{6}$, é o CelpeBras, em conjunto com o PEC-G, que conta com o maior número de trabalhos. Porém, entre os não listados, é o extinto Programa CsF, que apresenta um número mais significativo. No total foram citados seis programas de governo, entre extintos e ativos: CelpeBras, PEC-G, CsF, IsF e Programa Leitorado.

\section{LENTES DE PERSPECTIVA: AMPLIANDO AS TEMÁTICAS}

\subsection{PROGRAMAS DE GOVERNO}

\subsubsection{Promoção do português como língua estrangeira/adicional}

O Celpe-Bras, criado em 1994, é o exame brasileiro oficial para certificar proficiência em português como língua estrangeira/adicional (PLE/A), aplicado no Brasil e no exterior pelo Instituto Nacional de Estudos e Pesquisas Educacionais Anísio Teixeira (Inep), com apoio do Ministério da Educação (MEC) e em parceria com o Ministério das Relações Exteriores (MRE) (BRASIL, 2019c).

O PEC-G oferece a estudantes de países em desenvolvimento (África, Ásia e Américas), com os quais o Brasil mantém acordo educacional, cultural ou científico-tecnológico, estudos de graduação em Instituições de Ensino Superior (IES) brasileiras. É administrado pelo MRE, por meio da Divisão de Temas Educacionais (DCE), pelo MEC/Capes e Ministério da Ciência, Tecnologia e Inovação (MCTI), por meio do Conselho Nacional de Desenvolvimento Científico e Tecnológico (CNPq) (BRASIL, 2019d). Temse também o Programa de Estudantes-Convênio de Pós-Graduação(PEC-PG), porém este não foi citado em nenhum dos trabalhos.

Por ser o PEC-G um programa que visa receber estudantes de outros países, por meio de intercâmbio estudantil, a língua portuguesa se torna um elemento importante para a entrada dos alunos nas IES brasileiras. Segundo o Decreto nº 7.948/2013, que dispõe sobre o programa, é necessário para a inscrição, apresentar o Celpe-Bras ou realizá-lo no Brasil, após conclusão do curso preparatório, em IES credenciadas (BRASIL,2013).

Além do Celpe-Bras e do PEC-G, destacamos o Programa Leitorado. Esse programa financia professores interessados em promover a língua portuguesa, em sua vertente brasileira, além de divulgar a cultura, literatura e estudos brasileiros em IES estrangeiras. As vagas para leitor, função regulamentada pelo MRE desde 1999, é uma parceria com a Capes (BRASIL, 2019e).

Entre os estudos levantados, três ressaltam a relação/vinculação entre o Celpe-Bras e o PEC-G; e três ressaltam a promoção do PLE/A, pelo Programa Leitorado ou por algum programa local, como o Projeto Pelo Mundo (desenvolvido por professores da Universidade Federal de Minas Gerais - UFMG), totalizando seis trabalhos. Assim sendo, esses estudos tratam da promoção da língua nacional, especialmente, por meio de programas específicos de políticas nacionais.

Apresentamos, a seguir, o título desses estudos e a continuação de seus objetivos e contribuições. Adotaremos esse formato, também, nas demais seções.

1. Política linguística do Estado brasileiro na Contemporaneidade: a institucionalização de mecanismos de promoção da língua nacional no exterior (DINIZ, 2012)

2. Narrando o exame Celpe-Bras e o convênio PEC-G: a construção de territorialidades em tempos de internacionalização (BIZON, 2013)

\footnotetext{
${ }^{6}$ Em consulta recente à página do MEC, os programas citados e identificados no final de 2019 não foram mais localizados, entre eles: Celpe-Bras; PEC-G; Programa de Mobilidade Acadêmica Regional em Cursos Acreditados (Marca); Programa Milton Santos de Acesso ao Ensino Superior (Promisaes), IsF. Na página, atualmente, é citado apenas o Programa Universidades e Institutos Empreendedores e Inovadoras (Future-se), apelidado de Fundo Soberano do Conhecimento, programa dividido em três eixos: I - gestão, governança e empreendedorismo; II - pesquisa e inovação; e III - internacionalização (BRASIL, 2019b).
} 
3. Interfaces entre ações oficiais e as políticas linguísticas para a promoção internacional do português (SILVA, 2015)

4. Projeto "Pelo Mundo": A configuração de uma Política Linguística em um curso de Português como língua adicional para candidatos ao Programa de Estudantes-Convênio de Graduação (PEC-G) (MIRANDA, 2016)

5. O exame Celpe-Bras: mecanismo de política linguística para o programa estudantes-convênio de graduação (PEC-G) (DIONISIO, 2017)

6. Programa de Leitorado: diálogo entre política linguística externa e formação de professores de PFOL no Brasil (OLIVEIRA, 2017)

Diniz (2012), ao analisar algumas ações do Estado brasileiro para a promoção internacional do português, observa um fortalecimento da PL, devido à economia, a mudanças na política externa e ao imaginário do país no exterior. O autor adverte que as iniciativas são, geralmente, de política cultural e não de ensino de língua, fazendo com que a cultura seja um elemento-chave na mercantilização do português.

O trabalho de Bizon (2013) apresenta a narrativa de alunos do Congo quanto à preparação para o exame Celpe-Bras e ao período de graduação pelo PEC-G. O exame foi apontado como um importante instrumento de inserção nas relações sociais e acadêmicas, já o PEC-G como um instrumento que restringe essa inserção, marcada por preconceitos e exclusões. A autora indica a necessidade de repensar o funcionamento desse programa.

Silva (2015) analisa a interface entre políticas oficiais (Programa de Leitorado e de testes de proficiência) para a promoção de PLE/A dos Estados lusitano e brasileiro e a visão desse processo por gestores e professores que atuam na difusão internacional do português. Para a autora, existe um distanciamento entre a política explícita dos Estados e as necessidades percebidas, principalmente, no tocante à variedade e às especificidades no espaço geolinguístico. Com isso, a autora ressalta a importância de ações a partir do binômio língua-cultura, em que o português funcione como hiperônimo, uma unidade estratégica, bem como a necessidade de ações comuns e coletivas de formação de professores e do ensino de PLE/A entre os países.

O trabalho de Miranda (2016) analisa um curso de PLE/A (Projeto pelo Mundo) para candidatos ao PEC-G elaborado dentro da proposta dos letramentos críticos. Os resultados apontam para visibilização dos estudantes e de suas inquietações e para uma formação crítica baseada em uma PL pluricêntrica. O estudo ressalta a necessidade de projetos mais amplos e frequentes, que criem vínculos institucionais para favorecer a interculturalidade.

Dionísio (2017) investiga as crenças de alunos do PEC-G quanto ao papel do PLE/A e do exame Celpe-Bras. Foram verificadas crenças divergentes sobre a importância do português, e ressaltado o grau de exigência do exame. Como aspecto negativo, foi ressaltado que o exame determina o planejamento, os conteúdos, a metodologia e a avaliação, mas ao mesmo tempo, positivamente, propõe práticas comunicativas previstas pelos alunos. Segundo o autor, a pesquisa busca contribuir para a construção de uma visão multidimensional e multicamadas de política linguística.

Oliveira (2017) trata especialmente da formação de professores de português para falantes de outras línguas (PFOL) e do Programa de Leitorado. A autora busca revelar o que o perfil de ex-leitores e suas experiências sugerem. A discussão gerou a percepção de que pontos de fragilidade caracterizam a execução do Programa, apontando, assim, para a necessidade de reconfigurações, com a proposição de um curso voltado à formação de futuros leitores, e de repensar sobre a formação de professores de PFOL.

A promoção do PLE/A e o exame para sua certificação (Celpe-Bras) são políticas vinculadas, principalmente, ao PEC-G e ao Programa Leitorado. Os estudos problematizam a necessidade de repensar a estrutura desses Programas, no tocante à ideia de língua e cultura, ao nível de exigência do exame, acolhimento, exclusão/inclusão e formação de professores. 
Na continuação apresentamos os trabalhos que fazem referência ao Ciências sem Fronteiras (CsF) e ao Idiomas sem Fronteiras (IsF). Esses programas tiveram, assim, como o Celpe-Bras e o PEC-G, uma relação muito direta entre si. Foram encontrados cinco trabalhos que discutem o CsF e quatro que focam o IsF. Separamos os trabalhos em dois grupos, porém entendemos que, de certa forma, eles estiveram imbricados.

O Ciência sem Fronteiras, criado em 2011 e extinto 2017, tinha como objetivo promover a consolidação, expansão e internacionalização da ciência e tecnologia, da inovação e da competitividade brasileira por meio do intercâmbio e da mobilidade internacional de alunos de graduação e pós-graduação. O programa foi uma iniciativa dos Ministérios da Ciência, Tecnologia e Inovação (MCTI) e do MEC, com suas respectivas instituições de fomento - CNPq e CAPES -, e Secretarias de Ensino Superior e de Ensino Tecnológico do MEC (BRASIL, 2019f). Desde 2017, tem-se o Programa Institucional de Internacionalização, da Capes (CAPES-PrInt), que apesar de não ser continuidade do CsF, visa fomentar a internacionalização, porém, focada nos cursos de pósgraduação (BRASIL 2019g).

A seguir elencamos os estudos que versam sobre o CsF:

1. Avaliação da política linguística para o ensino de línguas estrangeiras: o impacto linguístico no programa ciências sem fronteiras (SOUZA, 2013)

2. Ciência sem Fronteiras: os sentidos de ciência em uma política pública do Estado brasileiro (LOPES, 2016)

3. Second language identity and study abroad: brazilian experiences in the science without borders program (SILVA, 2017)

4. (Sem/com) fronteiras: dispositivos de governamentalidade que atravessam o discurso sobre o programa ciência sem fronteiras UTFPR-FB (LINGNAU, 2017)

5. Deixa-me ir e vir - canta o Rouxinol: reminiscências docentes e política linguística de internacionalização para uma ciência sem fronteiras (ARAÚJO, 2018)

Souza (2013) avalia as PLs para o ensino de LE/A implementadas no Brasil, no tocante aos programas de mobilidade acadêmica, especialmente, o CsF. Conclui que o perfil linguístico mensurado por exames de proficiência, que se baseiam no modelo europeu, não faz parte da PL vigente brasileira, o que gera, desencontro, do tipo linguístico-educacional, entre o perfil exigido para mobilidade e o ensinado nas escolas.

Lopes (2016) observa quais sentidos de "ciência" foram produzidos nos textos institucionais e oficiais do CsF e a relação com os sujeitos. Conclui que produzimos ciência induzidos por interesse de diversos setores, e que o CsF reforça o sentido de ciência à serviço da sociedade.

Silva (2017) busca investigar de que forma ex-participantes do CsF tiveram suas identidades linguísticas em inglês reconstruídas, em trocas linguísticas entre nativos e não-nativos. Observou que as interações com falantes de diversas origens etnolinguísticas proporcionadas pelo CsF contribuíram para construção de suas identidades linguísticas em inglês, possibilitando repensar a figura do falante nativo como única referência para o aprendiz.

Lingnau (2017) buscou analisar os dispositivos de governamentalidade que mobilizam o discurso sobre o CsF, por meio de narrativas de participantes do CsF, nos Estados Unidos. O autor percebe que o CsF esteve conectado ao momento histórico de cada um dos envolvidos. Ressalta ainda o obstáculo do Quadro Comum Europeu de Referência para Línguas (QCER) e dos exames internacionais para ter acesso às IES e empresas no exterior.

Araújo (2018) problematiza os entraves linguísticos vivenciados por bolsistas do programa CsF, relativos à falta de proficiência em língua inglesa (LI). Seu estudo revela que a linguagem é o principal mecanismo de restrição da mobilidade, e ressalta que professores de línguas e as licenciaturas foram utilizados como agentes locais das dimensões cultural, internacional e global e excluídos do programa de mobilidade. A autora conjetura que conferir o direito à mobilidade internacional aos professores de LI poderia ser um caminho proveitoso para estabelecer um ensino de LI de qualidade no Brasil.

Forum lingüístic., Florianópolis, v.18,n.1, p.5596-5617, jan./mar.2021 
Os estudos que discutem o CsF enfatizam, desse modo, o perfil exigido nos exames de proficiência, os sentidos e o papel dos programas (interesses e objetivos), a contribuição das interações entre os participantes e o acesso dos alunos e professores de línguas (especialmente de LI) ao programa. Tais estudos problematizam, ainda, o desencontro entre as exigências globais/locais e a reprodução de modelos hegemônicos na realidade brasileira, como o QCER e os exames de proficiência.

Podemos dizer, que, no Brasil, a principal política linguística para a internacionalização da educação foi o Inglês sem Fronteiras, criado em 2012, que passou a integrar o Idiomas sem Fronteiras (IsF), em 2014, por meio de alteração na portaria anterior, extinto em 2019. O IsF visava preparar linguisticamente alunos de universidades brasileiras para programas de mobilidade ofertados pelo Governo Federal, mais especificamente, o CsF. Nesse cenário, ações de natureza linguística para a fomentação do processo de internacionalização são justificadas sobretudo pela necessidade da capacidade de comunicação para práticas específicas e pontuais de internacionalização, como a mobilidade e o intercâmbio acadêmico.

Apesar de o CsF ter sido extinto em 2017, o IsF prosseguiu com iniciativas locais ${ }^{7}$. Em 2020, por meio da Portaria ${ }^{\circ}$ 103/2020, a Capes criou uma comissão para produzir estudos técnicos para viabilizar ações linguísticas de acolhimento, mobilidade e internacionalização no contexto da pós-graduação. Trata-se da proposição de modelos de oferta de cursos pilotos, na esfera digital, que viabilizem o desenvolvimento da competência comunicativa, midiática e científica de alunos e professores da pós-graduação (BRASIL, 2020).

A seguir apresentamos os trabalhos referentes à temática IsF:

1. Efeito retroativo de um exame de proficiência em língua inglesa em um Núcleo de Línguas do programa Inglês sem Fronteiras (KOBAYASHI, 2016)

2. Um Everest que eu vou ter que atravessar: formação de professores para o ensino de inglês acadêmico no programa de Idiomas sem Fronteiras (VIAL, 2017)

3. O programa Inglês sem Fronteiras como política linguística: um estudo sobre as ideologias da língua inglesa no âmbito da internacionalização do ensino superior brasileiro (PASSONI, 2018)

4. O papel da competência simbólica no processo de internacionalização da educação superior brasileira: fronteiras linguísticas e o Idioma sem Fronteiras. (LEGG, 2019)

Kobayashi (2016) traz uma reflexão sobre a relação entre exame de proficiência e PL, ao analisar a influência da necessidade de um certificado internacional de proficiência em inglês, no caso o exame TOEFL IBT ${ }^{8}$, para a participação no CsF, em cursos presenciais do IsF. Os resultados demonstraram efeito retroativo no formato, conteúdo e material didático do curso preparatório, não havendo o mesmo efeito nas aulas de outros cursos.

Vial (2017) analisou momentos de formação docente para o ensino de Inglês para Fins Acadêmicos (IFA) vivenciados por professores-bolsistas no contexto de um Núcleo de Línguas (NucLi) do IsF, ao longo de oito meses. A autora concluiu que os momentos de formação oportunizaram aprender e praticar IFA e refletir sobre o seu ensino a partir de três iniciativas: preparação para os testes de proficiências, reuniões pedagógicas-administrativas e aulas de leitura/escrita acadêmica. Os momentos de formação oportunizaram aos alunos perceberem a diferença entre IFA e inglês geral; e a desenvolverem conhecimentos para ministrarem esse tipo de curso.

\footnotetext{
${ }^{7} \mathrm{O}$ IsF passou a ser reconfigurado pela Associação Nacional dos Dirigentes das Instituições Federais de Ensino Superior (Andifes) e continuado em algumas instituições por meio da Rede Andifes Nacional de especialistas em língua estrangeira - Idiomas sem Fronteiras (Rede Andifes-IsF).

${ }^{8} \mathrm{O}$ teste TOEFL IBT (Test of English as a Foreign Language - Interned Based Test) avalia a capacidade de usar e compreender o inglês no nível universitário, na capacidade de combinar as habilidades de ler, escrever, escutar e falar para realizar tarefas acadêmicas.
}

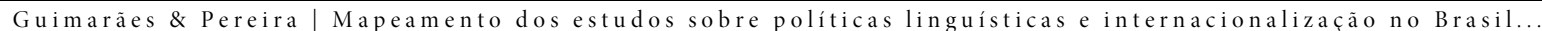


Passoni (2018) buscou investigar o programa IsF como uma PL produzida no âmbito da internacionalização do ensino superior brasileiro, com foco nas ideologias da língua inglesa (ILI). A autora defende que o IsF é uma PL permeada por seis ideologias: língua padrão, língua inglesa como mercadoria, falante nativo, instrumentalista, língua global e imperialismo linguístico.

Legg (2019) examinou se, e em que grau, as práticas pedagógicas do programa IsF de uma universidade promovem o desenvolvimento da Competência Simbólica (KRAMSCH, 2006), a partir da observação de duas aulas ministradas em cursos distintos, dos materiais didáticos utilizados nestas aulas e de entrevistas com os professores ministrantes. Os resultados sugerem que o desenvolvimento da Competência Simbólica não é observado em alto grau a partir das práticas pedagógicas do programa, embora haja potencial para seu desenvolvimento.

Os estudos sobre o IsF enfatizam a preparação para os exames internacionais, a organização de cursos para esse fim, as competências desenvolvidas e as ideologias relacionadas às LE/A, principalmente, à LI. Cabe ressaltar, que o IsF como PL para internacionalização ofertava, além de testes de nivelamento e proficiência (para editais de mobilidade), cursos de línguas em universidades cadastradas como Núcleos de Línguas (Nucli) do Programa. E que, apesar de o curso online (curso My English Online - MEO) ser para o inglês, os Nucli poderiam ofertar outras LE/A, e também, PLE/A.

\subsection{SENTIDOS / PROCESSO DE INTERNACIONALIZAÇÃO DA EDUCAÇ̃̃O}

As ações por meio de políticas implementadas pelo governo são poucas; sendo assim, algumas IES efetivam o processo de internacionalização a partir de sua autonomia, definindo individualmente suas necessidades de acordo com os objetivos do plano de metas da instituição (STALLIVIERI, 2004). Os trabalhos a seguir apresentam os esforços das instituições nesse sentido, além de discutirem a internacionalização numa perspectiva mais ampla, problematizando sua complexidade.

1. Entre fios, pistas e rastros: os sentidos emaranhados da internacionalização da Educação Superior (MARTINEZ, 2017)

2. O processo de internacionalização no ensino superior brasileiro: um estudo de caso sobre a universidade estadual do Paraná (ZAMBONI, 2018)

3. Internacionalização na UTFPR-CT: da cereja do bolo às duas pontas do iceberg (PAZELLO, 2019)

Martinez (2017) problematiza sentidos que constituem o cenário da internacionalização da IES, em duas universidades públicas brasileiras. Seu ponto de partida está no pressuposto de que internacionalização, globalização, capitalismo e neoliberalismo estão imbricados e precisam ser analisados criticamente. Os resultados apontam para uma mudança de base epistemológica na relação entre Sul e Norte Global, e para a necessidade de mais atenção para a interculturalidade como aspecto central da internacionalização.

Zamboni (2018) investigou de que modo se estabelece o processo de internacionalização em uma universidade pública. Concluiu que para que a internacionalização se desenvolva de modo mais efetivo é necessária a implantação de PLs consistentes e disponíveis a todo o corpo acadêmico, que englobam o desenvolvimento de competências em LE/A, além de que se estabeleça uma articulação coletiva e substancial entre todos os setores institucionais.

Pazello (2019) investigou como o conceito de internacionalização é percebido em uma universidade federal e como ele reflete na instituição, enfocando a emergência do contexto linguístico-pedagógico docente e suas características. Os resultados revelaram uma internacionalização passiva que gira em torno da mobilidade acadêmica, que incorpora o sentido de educação como serviço prestado para atender as demandas do mercado neoliberal, e que reconhece a LI juntamente com o professor como essenciais para a realização das ações. Entretanto, para a autora, essas evidências podem ser ressignificadas por epistemologias do pluralismo, as quais colocam a diversidade como inerente a todas as interações e estimula uma educação linguística integral.

Esses trabalhos buscam problematizar sentidos, vozes dos envolvidos, bem como aspectos naturalizados da internacionalização, como: as relações assimétricas de cooperação, a centralidade na mobilidade e a educação como serviço. Propõem ressignificações 
baseadas no pluralismo, na interculturalidade, no desenvolvimento de competências, no deslocamento da hegemonia do inglês como língua da ciência e na articulação coletiva.

\subsection{ESTRATÉGIAS DE INTERNACIONALIZAÇÃO}

Para Knight (2004), o termo estratégia de internacionalização refere-se a iniciativas organizacionais e programáticas em nível institucional, que vão além de atividades internacionais, pois incluem uma abordagem planejada e integrada e são implementadas por meio de programas. Assim, as estratégias de internacionalização podem ser: programas acadêmicos (intercâmbio, mobilidade, estudos de LE/A, internacionalização do currículo); pesquisa/colaboração acadêmica (projetos conjuntos, seminários, publicações, acordos); relações exteriores domésticas e transfronteiriças (parcerias e projetos) e atividades extracurriculares (eventos, grupos).

Entre os estudos observamos estratégias no currículo, dupla diplomação, formação de professores, cursos (centro) de línguas, regionalização em casa e mobilidade (que trataremos à parte, devido à quantidade significativa de estudos).

1. Construções de entre-lugar sociocultural de professores brasileiros e ingleses na implementação de um novo currículo em uma escola internacional (GONÇALVES, 2013)

2. Faces do agir docente em projetos cooperativos de internacionalização: representações sobre políticas de idiomas estrangeiros no contexto dos Institutos Federais (CAVALCANTE, 2016)

3. A formação de professores e o Programa de Licenciaturas Internacionais (PLI): experiências de licenciandos em Letras da UFV (SILVA, 2017)

4. A representação do discurso acadêmico nos textos do livro skillful e sua relação com a internacionalização do ensino nas universidades brasileiras: aspectos culturais e identitários (ÁVILA, 2017)

5. Ensino de inglês e a internacionalização do ensino superior: percepções sobre o Programa "Paraná Fala Inglês" (MARSON, 2017)

6. Desafios na Regionalização em Casa quanto à formação de docentes de línguas adicionais, um estudo de caso no MERCOSUL: para integrar necessitamos de professores (Web) (CAÑETE, 2018)

7. Francês para Relações Internacionais: investigando ações de ensino e de aprendizagem em uma formação de Francês para Objetivo Específico (OFERICE, 2019)

Gonçalves (2012) discute questões interculturais ao analisar construções identitárias e posicionamentos de professores brasileiros e ingleses, de uma instituição escolar bilíngue, diante da implementação de um novo currículo para educação internacional. A autora observa que os ingleses buscam fortalecer a cultura local, enquanto os brasileiros se dividem entre o local e a abertura para a internacionalização.

Cavalcante (2016) investiga as representações de educadoras (também assessoras de internacionalização) dos Institutos Federais (IF) ao empreender ações de implantação de uma PL de práticas de idiomas. Os resultados apontam que as Professoras Assessoras, ao se confrontarem com a inadequação das políticas públicas educacionais do Estado materializam uma proposta alternativa de PL por meio de Projetos de Centros de Idiomas (PCI).

Silva (2017) analisa o sentido atribuído pelos estudantes de Letras às experiências vivenciadas no âmbito do Programa de Licenciaturas Internacionais (PLI). Constatou que o PLI contribuiu para o desenvolvimento pessoal e profissional dos estudantes, o que poderia refletir positivamente em suas futuras atuações em sala de aula.

Marson (2017) buscou compreender como o Programa "Paraná Fala Inglês" (PFI) pode contribuir para a internacionalização do ensino superior. Os resultados mostraram ser necessário replanejamento nos âmbitos institucional e pedagógico, por meio da

\footnotetext{
${ }^{9}$ Lançado em 2014, com o apoio da Secretaria de Ciência, Tecnologia e Ensino Superior do Paraná (Seti), bem como da Unidade Gestora do Fundo Paraná (UGF), o programa "O Paraná Fala Inglês" (PFI) tem como principal objetivo apoiar o processo de internacionalização das instituições de ensino superior do Paraná (SETI, 2019).
}

Guimarães \& Pereira $\mid$ Mapeamento dos estudos sobre políticas linguísticas e internacionalização no Brasil.. 
ampliação da oferta e da variedade de LE/A, definição de uma PL com vistas à internacionalização e prioridade na formação da comunidade, articulação das diversas instâncias da universidade.

Cañete (2018) ressalta uma proposta de Regionalização em Casa entre o curso de Letras de uma instituição de ensino superior do Brasil, da Argentina e do Uruguai, a fim de analisar como os estudantes planejam e interagem no intercâmbio de conhecimento. Os resultados mostram que houve participação e cooperação entre o grupo, porém nem todas se engajaram da mesma forma com a tecnologia. O autor ressalta assim que para que haja um intercâmbio efetivo e engajado com as Tecnologias de Informação e Comunicação (TICs) é necessário compreender essa forma de trabalho, para que se possa regionalizar sem sair de casa.

Ávila (2017) buscou considerar a importância do livro didático, em meio ao processo de internacionalização, considerando-o como uma ferramenta veiculadora do discurso científico e, ao mesmo tempo, de sua contextualização sociocultural. Os resultados indicam que o discurso veiculado no livro analisado privilegia algumas áreas em detrimento de outras, fato esse que corrobora com alguns estereótipos sociais que presenciamos em nossa sociedade.

Oferice (2019) investiga as particularidades de elaboração e aplicação de um programa de ensino de Francês para Objetivo Específico (FOS) para Relações Internacionais (RI), com o foco na comunicação oral. Os resultados evidenciaram que aplicação de FOS está relacionada à dimensão autoral do material didático elaborado pelo professor, ao definir as especificidades, necessidades de comunicação oral em situações profissionais específicas com as quais os alunos-participantes se envolovem.

Esses trabalhos abordam atividades e programas específicos desenvolvidos pela instituição, por departamentos ou por grupo de professores e até mesmo individualmente. Muitas dessas pesquisas reforçam a importância de que as ações precisam de envolvimento pedagógico e institucional.

Destacamos que a maioria dos trabalhos foi realizada em contexto de formação de professores de línguas ou em contexto de atuação docente em curso. A internacionalização demanda, assim, o protagonismo docente na tomada de decisões. Os estudos ressaltam o trabalho docente na elaboração de cursos, de materiais didáticos, na consideração de estratégias mais produtivas ao contexto e aos alunos. Nesse sentido, vale destacar que a efetivação da internacionalização está condicionada à atuação dos professores. Nessa organicidade, os docentes passam a se constituir como agentes de PLs tanto na base quanto nas altas esferas sociais. Eles atuam como formuladores e agentes de política na microesfera escolar (SHOHAMY, 2006), enfrentando as restrições impostas pelos sistemas educacionais. Tornam-se agentes ativos na preparação sociocultural, linguística e política de seus estudantes.

\subsection{MOBILIDADE ACADÊMICA}

O deslocamento físico de estudantes, professores, técnicos e gestores de sua instituição de origem para outra tem sido apontado como o principal indicador, a forma principal de internacionalização, pois “[...] permite a preparação de estudantes que se tornarão profissionais com visões globalizadas, igualmente é importante pelos conhecimentos que aporta mediante seu retorno” (CAPES, 2017, p.31). Contudo, "[...] está evidenciado que a mobilidade é fator importante, mas insuficiente para internacionalizar uma universidade" (MOROSINI, 2019, p.19), além disso, beneficia apenas uma parcela dos estudantes.

Internacionalizar não é fazer da mobilidade acadêmica in (de recebimento) ou out (de envio) a atividade principal da internacionalização institucional. A internacionalização educacional pressupõe um enfoque mais integral baseado em processos (DE WIT, 2011).

Tais questões nos possibilitam refletir sobre o fato de que a internacionalização é um processo que não pode ser implementado de forma diluída unicamente em ações pontuais, como a de mobilidade acadêmica internacional, mas que precisa tornar-se intencional, no sentido de fazer parte de todos os eixos das instituições de ensino.

Aspectos da mobilidade acadêmica foram discutidos nos estudos a seguir. 
2. Avaliação e certificação em francês língua estrangeira para a mobilidade internacional de estudantes da Universidade de São Paulo (VOLTANI, 2015)

3. Formação para a mobilidade acadêmica na França na área de Letras: Da leitura literária ao commentaire linéaire francês (MORAES, 2016)

4. Letramentos Transculturais: Internacionalização, Mobilidade Discente e Formação de Professores de Língua Inglesa (PEREIRA JUNIOR, 2017)

5. Programa de Mobilidade Acadêmica Internacional da Universidade de Caxias do Sul: desafios linguísticos-culturais dos intercambistas (ROSA, 2018)

6. A Relação Sujeito-Língua (Portuguesa)-Identidade em Contexto de Intercâmbio Universitário: Autobiografias Linguageiras (VALENTIM, 2018)

Souza (2015) destacou representações de estudantes brasileiros em mobilidade estudantil sobre a França, antes e depois da experiência de intercâmbio pelo programa de Duplo Diploma. A autora levantou reflexões sobre representações culturais, impactos da experiência de intercâmbio e sobre a preparação linguística e cultural dos estudantes, durante o Curso de Francês para Iniciantes (CFI). Os resultados demonstram que as representações sociais e os estereótipos podem influenciar as relações sociais dos alunos no contexto acadêmico, demandando reflexão de tais aspectos quando na elaboração de cursos para mobilidade. A autora ressalta que a identificação positiva da cultura estrangeira motiva os alunos a aprenderem a língua. Destaca, ainda, que retratar a cultura, contribui para a consciência da diversidade e sensibilidade em compreender e respeitar o outro e a si mesmo.

Voltani (2015) discute características das avaliações de conhecimentos em língua francesa presentes nos processos seletivos para a mobilidade de estudantes de graduação da USP, buscando identificar os requisitos exigidos em língua francesa quando da publicação dos editais que definem os critérios das seleções, em editais da própria universidade e do CsF. Os resultados indicam que há diversidade de entendimentos sobre o nível exigido, bem como do valor social atribuído ao documento que atesta os conhecimentos na língua. Além disso, constatou a ausência de uma PL adequada ao contexto de internacionalização da USP, que se expressa na falta de clareza de dispositivos de formação e de avaliação para a preparação dos estudantes que realizarão atividades universitárias na França.

Moraes (2016) desenvolve e analisa um curso de extensão de Francês para Objetivo Universitário (FOU), com foco na compreensão de textos literários, ao verificar as dificuldades encontradas para a realização de leitura e produção escrita literária em língua francesa por alunos que planejavam realizar estudos na França. Os resultados apontam para a necessidade de preparação linguística, metodológica e cultural voltada para o desenvolvimento de um processo de leitura e produção do commentaire linéaire ${ }^{10}$ por meio de estratégias de estudo e compreensão dos textos literários.

Pereira Junior (2017) investigou o fenômeno da internacionalização por meio da mobilidade discente promovida na UFMG. Buscou compreender os efeitos da experiência internacional de três estudantes de licenciatura em inglês, no desenvolvimento de estratégias de mobilidade e na formação cidadã e profissional. Os resultados apontaram que as estratégias foram construídas por cada participante de acordo com suas trajetórias e históricos de vida, exigindo uma reflexão acerca das barreiras enfrentadas pelos alunos para a mobilidade. Os resultados também apontaram para a compreensão sobre as construções identitárias e as práticas sociolinguísticas dos estudantes que realizam mobilidade. Segundo o autor, tais apontamentos podem promover a melhoria dos programas já existentes e a implantação de novas estratégias de ação. Para isso, sugere a necessidade de se repensar as práticas de internacionalização adotadas pela instituição, com o objetivo de facilitar o acesso dos alunos em formação aos programas de mobilidade; e para a necessidade de valorizar o papel dos alunos para se tornarem professores na difusão de conhecimentos pertinentes às próprias práticas de internacionalização.

\footnotetext{
${ }^{10}$ Trata-se de "[...] uma produção escrita tradicional no contexto acadêmico francês e que tem, portanto, características específicas, a saber, explicação de um texto literário, a construção segundo a sequência da obra literária em que se baseia, a apresentação de uma análise baseada em forma e conteúdo do texto literário e a determinação de uma problemática que guie sua produção" (MORAES, 2016, p. 43).
} 
Rosa (2018) propõe atividades que contribuam com o Programa de Mobilidade Acadêmica da Universidade de Caxias do Sul (UCS), no sentido de colaborar com o desenvolvimento da competência comunicativa de alunos intercambistas recebidos na instituição, utilizando-se do quadro comum europeu, especificamente o Nível B1 de proficiência (nível intermediário). A autora discute a preparação linguística e cultural como forma de minimizar a insegurança linguística que surge nos processos de intercâmbio, e possibilitar a interação e o desenvolvimento da competência comunicativa. A autora concluiu que tanto os estudos culturais quanto a sociolinguística podem colaborar para que sejam produzidas atividades capazes não só de qualificar a competência comunicativa de alunos intercambistas, mas também propiciar a eles uma experiência cultural significativa.

Valentim (2018) busca refletir acerca da relação sujeito-língua-identidade de alunos francófonos intercambistas no Brasil. Partiu da hipótese de que a LE/A, ao ser vivenciada em imersão, modifica-se e modifica o próprio aprendiz. Os resultados evidenciam mudanças na identidade desses sujeitos-aprendizes por conta da vivência social da língua portuguesa no contexto imersivo, pelo sentimento de ser bem acolhido, pela conduta de não turista, como alguém que pode participar da comunidade linguística. O autor ressalta, ainda, que o relacionamento positivo em imersão e a busca em conhecer esse Outro são essenciais para se poder falar a língua, que é, ao mesmo tempo, alvo e meio dessa interação. O autor conclui que o intercâmbio potencializa a vivência com e por meio da língua-alvo e permite aos sujeitos serem valorados como alguém que fala português e a ocupar um entre-espaço, reconfigurando-se constantemente. Igualmente, a narração de sua autobiografia com a língua portuguesa e da experiência vivida no Brasil, permite-lhes construir uma nova percepção de si.

Os estudos elencados nessa sessão sobre mobilidade/intercâmbio discutem a preparação dos alunos, linguística e culturalmente, para as interações em contexto de mobilidade in e out, levando em consideração aspectos individuais, contextuais e identitários. E entre as preocupações tem-se a problemática do uso da língua, mas também os desafios culturais dos alunos intercambistas. Focaram, assim, no acesso dos alunos aos programas de mobilidade, na preparação para o deslocamento estudantil, no desenvolvimento da competência comunicativa, nos desafios culturais e linguísticos e na relação positiva dos alunos com a nova língua, cultura e com o outro.

\subsection{LETRAMENTOS ACADÊMICOS}

Segundo Rajagopalan (2015), a circulação das ideias, do saber científico, por meio de consultas bibliográficas, de e-books e livros completos na internet são circunstâncias a favor do pesquisador. No entanto, segundo o autor, a indústria da tradução não abarca a quantidade de produção vinda de várias partes do mundo, em sua maioria em inglês, o que acaba por exigir do pesquisador estar minimamente proficiente em língua inglesa. Tal panorama reflete a geopolítica da língua inglesa e o seu papel hegemônico no contexto linguístico-intercultural da internacionalização, fazendo com que a própria LI seja sinônimo de PL.

Shohamy (2006) explica que, apesar de algumas pessoas temerem que a LI domine o mundo e crie um código monolíngue, não há evidências para esse fenômeno. Conforme essa pesquisadora, no futuro, o padrão dominante será uma variedade de código múltiplo com línguas nacionais e locais que acompanharão a LI. Isso porque "[...] o Inglês usado em diferentes partes do mundo é contextualmente dependente e varia de um local para outro” (SHOHAMY, 2006, p. 13). Nesse sentido, as práticas de linguagem devem ser plurilíngues e pluriculturais, a fim de provocar a desconstrução de hierarquização linguística, a desmistificação da noção de falante nativo e o estímulo de interações linguísticas tolerantes e solidárias.

Os estudos a seguir discutem práticas de linguagem em contexto acadêmico.

1. Um Novo Jeito de Se Fazer Dissertação: Letramentos Acadêmicos e Internacionalização (NOGUEIRA, 2017)

2. Internacionalizar a produção acadêmico-científica brasileira: uma questão de língua, tradução e discurso (PASSINI, 2018)

3. A escrita em inglês na pós-graduação: dificuldades, convergências e divergências nas percepções de discentes e docentes (DANTAS-LUNN, 2018)

4. Políticas linguísticas e internacionalização acadêmica: entre o status da língua inglesa e a promoção do plurilinguismo (ANDRADE, 2019) 
Nogueira (2017) investiga práticas de letramento acadêmico em uma instituição brasileira de ensino superior e o impacto de tais práticas em sua internacionalização, no contexto de uma oficina oferecida para auxiliar acadêmicos que necessitam comunicar-se em inglês. A autora traz reflexões e exemplos no que diz respeito ao formato alternativo, mostrando que nem alunos, nem professores estão totalmente preparados para escrever e publicar em inglês. Descreve dimensões escondidas no processo de internacionalização e revela que a colaboração é fundamental na produção e divulgação de pesquisa. As práticas de letramento acadêmico são vistas, pela autora, como indispensáveis aos processos de internacionalização eficazes e integradores.

Passini (2018) propõe uma reflexão sobre tradução a partir de demandas do processo de internacionalização da produção de conhecimento acadêmico-científico brasileiro, devido a limitações de ordem linguística que emergem como uma questão a ser solucionada. Os resultados demonstram que essas traduções, predominantemente parafrásticas, indiciam seu valor na cultura de partida mais do que sua função na cultura de chegada. Assim, as traduções além de serem produzidas para facilitar o acesso entre diferentes línguas e culturas, assumem valor no sistema de avaliação da produção de conhecimento nacional.

Dantas-Lunn (2018) objetivou conhecer as dificuldades de pós-graduandos de uma universidade com a escrita acadêmica em inglês. As análises mostraram convergência entre alunos e docentes nas percepções das duas maiores dificuldades: escrever um texto que soe natural em inglês e usar preposições adequadamente. Segundo o autor, o conhecimento das dificuldades específicas poderá contribuir para melhor orientar futuras iniciativas pedagógicas e institucionais que beneficiem tanto pós-graduandos quanto professores.

Andrade (2019) ressalta, no contexto de internacionalização do ensino superior, aspectos da competência comunicativa, destacando as demandas de uso de LE/A na universidade. Essa demanda evidencia os distanciamentos existentes entre a precária formação em LE/A no ensino básico e as necessidades comunicativas do contexto acadêmico. Nesse sentido, a autora constata a necessidade de implementar uma PL universitária plurilíngue que dê conta da diversidade linguística envolvida no processo de internacionalização.

Esses estudos destacam as dificuldades dos alunos em relação ao uso da língua inglesa, especialmente, na produção de textos acadêmicos escritos. Para tanto, apresentam alternativas de ensino baseado na cooperação, na socialização da escrita, tradução, na educação plurilíngue, em gêneros textuais, em modelos híbridos, no feedback e no auto(conhecimento) das dificuldades encontradas no trabalho de letramentos acadêmicos

No âmbito das práticas de linguagem de internacionalização, em que se observa a importância da semiótica social e da multimodalidade, os multiletramentos constituem-se componentes essenciais, pois fornecem subsídios para que o indivíduo desenvolva a capacidade de compreender e analisar diferentes textos, de modo a lhes permitir engajar em situações globais de interação e fazer sentido a partir delas, o que ultrapassa a demanda que até então eles tinham de aprender a língua para algo específico (apenas para leitura e escrita de textos acadêmicos, apresentação oral em eventos etc.). O professor de línguas necessita, portanto, aproveitar de dificuldades e necessidades locais para o ensino-aprendizagem de línguas em diálogo crítico com os contextos internacionais.

Nessa perspectiva, as línguas no contexto de internacionalização, como prática social capaz de transformar relações, tornam-se uma estratégia que contribui não somente com a produção de conhecimento acadêmico-científico, mas também para a construção de uma sociedade mais justa e democrática e que se importa com os problemas de cunho global.

\section{CONSIDERACÕES FINAIS}

Este trabalho permitiu revelar a importância que os estudos sobre internacionalização e políticas linguísticas foram adquirindo no transcurso de uma década, principalmente, a partir da implementação de programas de governo, tais como o CsF e o IsF, extintos atualmente.

Guimarães \& Pereira Mapeamento dos estudos sobre políticas linguísticas e internacionalização no Brasil. 
Embora muito dos programas de governo e iniciativas locais tenham sido avaliados positivamente, surgiram expectativas de mudanças estruturais motivadas por questionamento quanto à formação do corpo docente, ao perfil internacional exigido nos exames, às necessidades globais-locais, às práticas de linguagem. Como sugestões, muitos dos trabalhos entendem a necessidade de: a) repensar e ressignificar os processos a partir dos quais a formação dos professores de línguas é gerenciada e construída; b) engajamento e protagonismo mútuo dos atores em um projeto conjunto para o planejamento e implementação de políticas; c) propostas mais alinhadas às necessidades da instituição e dos agentes; d) práticas de linguagem que façam sentido para os alunos em contextos não-institucionalizados dos quais participam; e) práticas que contribuam para a paz e a justiça social. Isso tudo implica uma reflexão crítica contínua sobre o fazer pedagógico, sobre as relações sociais, as relações de poder, o político e ético, os embates significativos de construção de sentidos, os conhecimentos e os direitos de aprendizagem no processo de internacionalização.

Notamos, ainda, que as PLs relacionadas ao PLE/A são na maior parte explícitas e nacionais, enquanto que as de LE/A são, muitas vezes, iniciativas institucionais ou de sala de aula. Portanto, cabe escutar as vozes de professores e alunos e as políticas de uma ótica bottom-up (de baixo para cima). O professor de línguas é um ator que faz política em seu campo prático, pois seu agir é sempre ativo e pressupõe decisões (CAVALCANTE, 2016).

No entanto, considerando que muitas exigências e desafios têm sido impostos aos docentes nos dias atuais, é relevante considerar as reflexões de Akkari (2011) sobre o fato de que a internacionalização gera novas formas de regulação das políticas educacionais como o aumento da pressão sobre os professores para prestarem contas de suas ações pedagógicas, entre outras. Dessa forma, para além dessa imposição, é necessário encorajar os professores a integrarem, intencionalmente, "[...] uma dimensão global, intercultural e internacional" (DE WIT et al., 2015) em sua prática, envolvendo transversalmente os eixos do ensino, da pesquisa e da extensão.

A análise de diferentes estudos indicou a existência de divergência entre as necessidades dos agentes e as apresentadas em documentos oficiais. É necessário, portanto, discutir e problematizar estratégias e ações de internacionalização locais, que acabam por reproduzir modelos alheios, sem considerar as vozes dos interessados.

Podemos perceber que duas narrativas se reproduzem ainda amplamente: internacionalização como mobilidade e a importância da comunicação em inglês no mundo global. Observamos, também, que a maioria dos estudos sobre mobilidade teve como foco a língua e cultura francesa para alunos brasileiros ou a língua portuguesa para alunos francófonos; e que estudos sobre os letramentos acadêmicos são em contexto de ensino de língua inglesa.

Entre as lacunas, destacamos, assim, a necessidade de estudos que contemplem outras LE/A, e de pesquisas que discutam alternativas para estratégias tradicionais de internacionalização, que vão ao encontro das necessidades de países do Sul Global, que promovam letramentos multimodais e críticos com o objetivo de dar acesso à construção de significados e ao rompimento de práticas hegemônicas e excludentes de linguagem.

A internacionalização da educação confere às línguas papel relevante, uma vez que práticas sociais são nutridas pela linguagem, na lógica multissemiótica e multimodal intrínseca das comunicações interacionais (linguísticas, midiáticas, visuais, audíveis, gestuais, espaciais etc.), especialmente na contemporaneidade. Apesar da estreita relação entre internacionalização e políticas linguísticas, é necessário promover a superação do processo de internacionalização da educação baseado em mitos e ações reducionistas que compreendem tão somente a participação em programas de mobilidade acadêmica, a realização de apresentações de trabalhos científicos em eventos internacionais, a escrita acadêmica etc. Diferentemente, concebe-se a internacionalização de maneira integral e transversal, no sentido de que ela se torna um elemento intimamente introjetado na tríade universitária e que, portanto, viabiliza impactos salutares na instituição e na sociedade.

Embora a internacionalização tenha se tornado ao longo dos anos um imperativo para muitas instituições, consideramos que ela deva ser um processo intencional de seus agentes, passando a se constituir um ethos do indivíduo/ator institucional e não apenas da instituição. Nessa perspectiva, a internacionalização é vista como uma atitude de engajamento intencionado em um mundo global 
na construção de sentidos de maneira mais diversa, plural, intercultural, ética, política, criativa e crítica no que tange às questões que importam à humanidade.

\section{REFERÊNCIAS}

AKKARI, A. Internacionalização das políticas educacionais: transformações e desafios. Petrópolis: Vozes, 2011.

BRASIL. Decreto Presidencial n 7948, de 12 março de 2013. Dispõe sobre o Programa de Estudantes-Convênio de Graduação (PECG). Brasília, 2013.

BRASIL. Ministério da Educação. Coordenação de Aperfeiçoamento de Pessoal de Nível Superior. Diretoria de Avaliação. Documento de Área. Área 41: Linguística e Literatura. Brasília, 2019a.

BRASIL. Ministério da Educação. FUTURE-SE. Brasília, 2019 b.

BRASIL. Ministério da Educação. Instituto Nacional de Estudos e Pesquisas Educacionais Anísio Teixeira. Certificado de Proficiência em Lingua Portuguesa para Estrangeiros. Brasília, 2019c.

BRASIL. Ministério das Relações Exteriores. Divisão de Temas Educacionais. Ministério da Educação. Secretaria de Educação Superior. Diretoria de Políticas e Programas de Graduação. Coordenação Geral de Relações Estudantis. Programa de EstudantesConvênio de Graduação (PEC-G). Brasília, 2019d.

BRASIL. Ministério da Educação. Coordenação de Aperfeiçoamento de Pessoal de Nível Superior. Programa Leitorado. Brasília, 2019e.

BRASIL. Ministério da Ciência, Tecnologia e Inovação. Ministério da Educação. Conselho Nacional de Desenvolvimento Científico e Tecnológico. Coordenação de Aperfeiçoamento de pessoal de Nível Superior. Ciência sem Fronteiras. Brasília, 2019 f.

BRASIL. Ministério da Educação. Coordenação de Aperfeiçoamento de pessoal de Nível Superior. Programa Institucional de Internacionalização (CAPES-PrInt). Brasil, 2019g.

BRASIL. Ministério da Educação. Fundação Coordenação de Aperfeiçoamento de Pessoal de Nível Superior. Gabinete. Portaria $n^{\circ}$ 103, de 21 de julho de 2020. Cria Comissão Especial destinada a produzir estudos técnicos sobre modelos de oferta de curso piloto que aumente a competência linguística de alunos e docentes da pós-graduação. Brasília, 2020.

CAPES. A internacionalização na Universidade Brasileira: resultados do questionário aplicado pela Capes. Brasília, Diretoria de Relações Internacionais, 2017.

CAVAlCANTE, R. P. Faces do agir docente em projetos cooperativos de internacionalização: uma leitura interacionista sociodiscursiva de representações sobre políticas de idiomas estrangeiros no contexto dos institutos federais. 2016. Tese (Doutorado) - Universidade Federal da Paraíba, Centro de Ciências Humanas, Letras e Artes, Programa de Pós-Graduação em Linguística, Cidade, 2016.

DE WIT, H. Internationalization of Higher Education: Nine Misconceptions. International Higher Education, n. 64, p. 6-7, 2011.

DE WIT, H. Reconsidering the Concept of Internationalization. International Higher Education, n. 70, p.6-7, 2013.

Guimarães \& Pereira Mapeamento dos estudos sobre políticas linguísticas e internacionalização no Brasil.. 
DE WIT, H. et al. Internationalisation of Higher Education. Brussels: European Parliament, Directorate General for Internal Policies, 2015.

FERREIRA, N. S. A. As pesquisas denominadas “estado da arte”. Educação \& Sociedade, ano XXIII, n. 79, p. 257-272, 2002. Disponível em: http://www.scielo.br/pdf/es/v23n79/10857.pdf. Acesso em: 18 nov. 2019.

GOVERNO DO ESTADO DO PARANÁ. Superintendência de Ciência, Tecnologia e Ensino Superior do Paraná (SETI). Fundo Paraná. Programa Paraná Fala Idiomas. Paraná, 2019.

GUIMARÃES, F. F.; FINARDI, K. R.; CASOTTI, J. B. C. Internationalization and language policies in Brazil: What is the relationship? Rev. Bras. Linguística. Apl., v. 19, n. 2, p. 295-327, 2019. Disponível em: https://doi.org/10.1590/1984-6398201913553. Acesso em: 14 ago. 2020.

HUDZIK, J. Comprehensive Internationalization: from Concept to Action. Washington: NAFSA Association of International Educators, 2011.

JOHNSON, D. C. Language policy. New York: Palgrave Macmillan: 2013.

KNIGHT, J. Internationalization remodeled definition, approaches, and rationales. Journal of Studies in International Education. Sage Publications, v. 8, n. 1, p. 5-32, 2004.

KRAMSCH, C. From communicative competence to symbolic competence. The Modern Language Journal, v. 90, n. 2, p. 249-252, 2006.

LIMA, M.C.; CONTEL, F. B. Internacionalização da Educação Superior: Nações Ativas, Nações passivas e a Geopolítica do Conhecimento. São Paulo: Alameda, 2011.

MORAES, A.C. A. de. Formação para mobilidade acadêmica na França na área de Letras: da leitura literária ao commentaire linéaire francês. 2016. Dissertação (Mestrado em Língua e Literatura Francesa) - Faculdade de Filosofia, Letras e Ciências Humanas, Universidade de São Paulo, São Paulo, 2016.

MOROSINI, M. Guia para a Internacionalização Universitária. Porto Alegre: EDIPUCRS, 2019.

OREGIONI, M.S. Aspectos sociales de la internacionalización de la investigación. Una propuesta de abordaje. Revista CTS, Buenos Aires, v. 10, n. 30, p. 199-229, 2015.

OREGIONI, M.S. La internacionalización universitaria desde una perspectiva situada: tensiones y desafíos para la región Latinoamericana. Revista Internacional de Educação Superior, Campinas, v. 3, n. 1, p. 114-133, 2017.

PERROTTA, D. La internacionalización de la universidad: debates globales, acciones regionales. Buenos Aires: UNGS, 2016.

RAJAGOPALAN, K. A geopolítica da língua inglesa e seus reflexos no Brasil: por uma política prudente e propositiva. In: LACOSTE, Y (org.). A geopolítica do inglês. São Paulo: Parábola Editorial, 2005. p. 135-159.

RAJAGOPALAN, K. O professor de línguas e a suma importância do seu entrosamento na política linguística do seu país. In: CORREA: D. A. (org.). política linguística e ensino da língua. Campinas, SP: Pontes Editores, 2014. p. 73-82 
RAJAGOPALAN, K. Políticas públicas, línguas estrangeiras e globalização: a universidade brasileira em foco. In: ROCHA, C. H.; BRAGA, D.B.; CALDAS, R.R. (org.). Políticas linguísticas, ensino de línguas e formação docente: desafios em tempos de globalização e internacionalização. Campinas, SP: Pontes Editores, 2015.

SANTOS, B. S. A globalização e as ciências sociais. 4. ed. São Paulo: Cortez, 2011.

SANTOS, B. S.; MENESES, M. P. (org.). Epistemologias do sul. São Paulo: Cortez, 2010.

SHOHAMY, E. Expanding language policy. In: SHOHAMY, E. Language policy: hidden agendas and new approaches. London: Routledge, 2006. p. 45-58.

STALLIVIERI, L. Estratégias de internacionalização das universidades brasileiras. Caxias do Sul: Educs, 2004.

STALLIVIERI, L. Internacionalização e intercâmbio: dimensões e perspectivas. Curitiba: Appris, 2017.

TEODORO, A. Globalização e Educação: políticas educacionais e novos modos de governação. São Paulo: Cortez, 2003.

VEIGA, C. G. História da Educação. São Paulo: Ática, 2007.

\section{(๑) $\circledast$}

